\title{
Teamwork is our legacy
}

\author{
O trabalho em equipe é o nosso legado
}

Flavio Kapczinski*

After almost 4 years of hard but always pleasant work in the Editorial Board of Trends in Psychiatry and Psychotherapy, former Revista de Psiquiatria do Rio Grande do Sul, it is now time to pass the baton. The past term was marked by strong debate, important decisions, but, above all, a solid and fruitful teamwork that I expect will remain present in the next board and for as long as possible. Here I express my sincere thanks to Associate Editors Jair Segal, Pedro Vieira da Silva Magalhães, and Rodrigo Grassi-Oliveira, all very involved with the journal activities, as well as to the Board of the Associação de Psiquiatria do Rio Grande do Sul (APRS), which has fully supported our actions over all these years.

Our work as editors was not free from challenges. Some of the challenges we had to face and decisions we had to make were extremely delicate and definitely not easy. Nor were they new to our board. For example, changing the publication language of our journal into English had been a desire of several boards before us. Previous editors were already aware of the need to start communicating in English so that our journal could finally be given full consideration by major indexing databases worldwide. Nevertheless, resistance was also perceived coming from the opposite direction, as we know that, in Brazil, a large number of practitioners still resist or experience difficulties reading in English. Our board decided that it was time to fight resistance and consistently shift our focus toward the international community.

With the change in publication language, soon another major obstacle emerged: the local title of our publication strongly contrasted with its ambition to go international. Again, after much debate, we finally decided to make the change. As stated in the editorial of the first issue published under the new title, this change was seen by the Editorial Board as not only desirable, but also necessary, i.e., as a natural evolution and as a recognition of the great efforts made by previous boards and that in one way or another contributed to keep the journal growing and consolidating. ${ }^{1}$

\footnotetext{
* Former Editor-in-Chief, Trends in Psychiatry and Psychotherapy. No conflicts of interest declared concerning the publication of this editorial. Suggested citation: Kapczinski F. Teamwork is our legacy. Trends Psychiatry Psychother. 2013;35(1):1-2. 
Another major step taken by our Editorial Board was the writing of the journal's own statute, formalizing its editorial independence in relation to the sponsoring institution, APRS. Again, we know that this is still a delicate topic in Brazil, but we decided to keep true to our goal and follow international guidelines. ${ }^{2}$ Luckily, best practices were already in place in our case, but we are proud to have taken this step further.Challenges are not over. The constant work of editors as gatekeepers is at the core of their journals' success. I strongly believe that the new board now taking over, led by Dr. Marcia Kauer-Sant'Anna, will continue our legacy of teamwork. I leave the Editorial Board proud of the decisions made and certain that the future holds great promise for our Trends in Psychiatry and Psychotherapy.

\section{References}

1. Kapczinski F, Segal J, Magalhães PVS, Grassi-Oliveira R. New title: Trends in Psychiatry and Psychotherapy. Trends Psychiatry Psychother. 2011;33(3):133-4.

2. Council of Science Editors. CSE's White Paper on Promoting Integrity in Scientific Journal Publications. http://www. councilscienceeditors. org/i4a/pages/index. $\mathrm{cfm}$ ? pageid $=3358$. Accessed 2013 Mar 20. 